DotT, N. M. (1967). Personal communication.

FRENCH, P. R. (1964). Clinical Surgery, pp. I-13. Eds. C. Robb and R. Smith. London: Butterworths.

Geisler, W. O., Wynne-Jones, M. \& Jousse, A. T. (1965). Proc. IIIrd int. Congr. Neurol. Surg., Copenhagen. Excerpta Medica I.C. Series, No. I IO, pp. 347-352.

GreGG, T. M. \& Wilmot, C. B. (1964). Int. F. Paraplegia, 2, I5.

Guttmann, L. (1953). Medical History of the Second World War: Surgery. Ed. Z. Cope. London: H.M. Stationery Office.

GutTMAnN, L. (I962). Mth. Bull. Minist. Hlth Lab. Serv. 21, 60.

HARRIs, P. (1963). Spinal Injuries, pp. IOI-I02. Ed. P. Harris. Royal College of Surgeons of Edinburgh.

Harris, P. (I965). Proc. IIIrd int. Congr. Neurol. Surg., Copenhagen. Excerpta Medica I.C. Series, No. I Io, pp. 347-352.

KaHN, E. A. (I959). F. Bone ft. Surg. 4I-A, 6.

KERR, W. G. (I967). Personal communication.

LAMB, D. W. (1967). Personal communication.

Meirowsky, A. M. (1965). Neurological Surgery of Trauma, pp. 289-290. Ed. A. M. Meirowsky. Department of the Army, Washington, D.C.: Office of the Surgeon General.

Munro, D. (1945). Clinics, 4, 448.

NeWsam, J. E. (1967). Personal communication.

Robinson, J. S. (I966). Proc. R. Soc. Med. 59, I293.

Rossier, A. (1963). F. int. Coll. Surg. 39, 225.

Smithells, R. W. (1965). Proceedings of a Symposium on Spina Bifida. National Fund for Research into Poliomyelitis and Other Crippling Diseases. Vincent House, Vincent Square, London, S.W.I.

\title{
ON THE IMPORTANCE OF INDIVIDUALISATION OF SPINAL UNITS IN HOSPITAL ORGANISATION
}

\author{
By Victor Gaspar, M.D. \\ Urological Department of the Military Hospital in Oporto, Urologist to the \\ Francisco Noronha Hospital (Recuperation Centre for the Physically \\ Disabled), Portugal
}

OUR views are based on the experience which, as urologists at a recuperation centre for the physically disabled, we have acquired regarding the treatment of paraplegic patients.

All the patients had been sent to us from diverse hospitals, being referred usually from neurological or orthopaedic departments.

We have dealt with 65 paraplegics over a five-year period; in 7.5 per cent. of these the paraplegia was the result of non-traumatic lesion affecting the spinal cord; in the remaining cases the paraplegia succeeded a spinal injury. Only a minimal percentage $(5 \cdot 6)$ reached this centre within the first month following the accident, and of the remainder, 54.3 per cent. arrived here after more than three months. Almost all of them were suffering from complications which endangered their rehabilitation.

After investigating the causes of and classifying the frequency of those complications the results were as follows: 
Trophic Alterations of the Skin $(60 \cdot 4$ per cent.). Those were chiefly bedsores, solitary or multiple, simple or complicated at all stages of their evolution. We have found that the most frequent causes are:

I. Unsuitable bedding (standard hospital beds).

2. No regular turning of the patient.

3. Lack of care and of training in prophylaxis.

Orthopaedic Complications ( 43.7 per cent.). The most important complications in this group were ankylosis, the pronounced atrophy of the muscular masses and the defective attitude of the limbs. Responsible for these changes we have found:

I. Lack of proper care.

2. Indifference concerning the correct attitude of the limbs.

3. Neglect of early physiotherapy.

Urinary Complications $(20.4$ per cent.). The above number does not include the common urinary infection, which has been an almost constant occurrence. We have included only such urinary complications as urethral diverticuli and renal or vesical calculi. The causative factors were:

I. Lengthy periods of constant bladder catheterisation.

2. Use of rigid catheters.

3. Untimely catheterisation.

4. Lack of a sufficient intake of fluids.

We infer from the above data that, for the most part, those complications are the result of errors of concept, ignorance of the therapeutic rules, faulty equipment and absence of well-trained staff.

For those who know as well as we the sombre evolution of complications of this kind, it is easy to deduce how much they have militated against rehabilitating activities. The consequences can thus be enumerated:

I. Lengthening of the period of recovery.

2. Increase of the cost of hospitalisation.

3. Weakening of the patients' morale.

4. Lack of co-operation on the part of relatives and responsible authorities.

The facts we have stated above, and of which we are not proud, have given us a clear and definite picture of the defects.

Since the last world war there have been numerous reports concerning the pathology and therapy of patients suffering from vertebral or spinal cord lesions (especially those following an injury), and which are most frequent owing to the mechanisation of the present times. Few have stressed, however, the particular problems of this special class of patient who need a sound knowledge of expert of several branches of medicine.

As we have stated above, every one of these patients had been cared for at neurological or orthopaedic departments during a more or less lengthy period of time. From this management have resulted some unfortunate consequences to certain organic areas, as shown by the list of complications. 
The paraplegic - and by that we mean every patient with a spinal cord affliction at whatever level - cannot be adequately dealt with in any single department in a general hospital. It is imperative to obtain the help of urologist and physiologist as well as neurologist and orthopaedic surgeon.

The balanced and closely co-ordinated interpretation of the various data makes possible a correct clinical evaluation and suitable rehabilitation.

From this reasoning results a therapeutic pragmatism, which is multiclinical for its origins and unitarian for its objectives. This pragmatism, springing from this concept, new in medical practice, compels us to accept the creation of a new speciality of paraplegia. This is a branch with specific characteristics and which does not confine its activities to the clinical healing of this or that bodily areawhether motor or sphincters-but tries to go further. It aims at making the patient free from the hospital, through his reintegration in the society.

To achieve this, a spinal unit also profits from the experience of psychiatry and social rehabilitation.

A spinal unit necessitates complex and intricate experience and knowledge which must be applied to the patient from the onset of his illness. Any deviation from this plan will militate against the patient and may arise from lack of equipment, faulty training and an inopportune action at some stage of the paraplegia.

As a result of all this we have the axiom, so many times repeated and so frequently forgotten, which states that 'the future of a paraplegic is decided within the 48 hours following the accident'. The appearance of bedsores, the onset of urinary infection, an ankylosis that ruins a joint, all make the prognosis of rehabilitation more difficult, as any of these complications can obstruct the process of recovery.

All of us know that, generally speaking, the complications can be prevented in the majority of instances by the use of simple methods and technical details, together with meticulous care in every action. This simplicity of method is intrinsically the foundation of the achievement of good results. It is essential however, to be well acquainted with the pragmatics of the respective branch, to accept, to understand and put into practice these simple but essential rules. Its execution is only possible with strict rules and an experienced staff, sometimes difficult to achieve in otherwise differentiated departments.

The above facts and arguments are the basis of, and the justification for, the creation and individualisation of a spinal unit. The spinal unit, owing to its specific function, must be an independent unit, suitably and functionally integrated with the hospital structure, but must never be a secondary or complementary department. It must be able to receive immediately paraplegics admitted to any other departments after injury.

We can say, to bring this report to its conclusion, that only the confusion of concepts, the ignorance of possibilities, the inco-ordination of means and the inadequacy of hospital buildings have given to date a poor service for the care of paraplegics resulting in haphazard methods and poor results.

The paraplegic, because of his complex pathology, has the right to have an independent specialised form of care which will give him the hope in his first hour of illness, that is 'a return to society'. 